\title{
Crescimento das cidades médias e interiorização da migração: realidade ou mito?
}

\author{
Késia A. A. Silva \\ José Marcos P. da Cunha \\ Raquel Alonso
}

\section{Resumo:}

O objetivo deste trabalho é analisar o papel das cidades de porte médio no processo de interiorização. Este artigo tem como base o pressuposto de que, nas últimas décadas, se observou uma concentração da população em um número reduzido de cidades, sendo estas caracterizadas principalmente pelo porte populacional expressivo, e em grande parte localizadas em regiões metropolitanas. Nesse sentido, este trabalho questiona se o crescimento desta tipologia de municípios não estaria relacionado à expansão das regiões metropolitanas (e à emergência de uma nova morfologia urbana), ou se de fato estaria ocorrendo uma interiorização da população. Assim, foram classificadas como cidades de porte médio aquelas com população entre 100 e 500 mil habitantes, e foram analisados o crescimento e os fluxos migratórios dos municípios localizados em regiões metropolitanas e fora destas, no estado de São Paulo, nos anos de 2000 e 2010.

\section{Introdução:}

A questão do aparecimento, crescimento e o papel das chamadas "cidades médias" é objeto de preocupação de pesquisadores, planejadores e governantes e tem sido motivo de certas considerações que, por vezes, beira o chamado "senso comum".

De fato, não é difícil encontrar nos discursos dos mais variados especialistas a alusão do crescimento desta tipologia de municípios e sua importância na rede de cidades brasileiras, trabalhos como os de ANDRADE (1976), ANDRADE e LODDER, PEREIRA e FURTADO (2011), ARAUJO, MOURA e DIAS (2011), entre outros - fizeram contribuições relevantes dentro desta temática. Embora não seja menosprezada tal preocupação, pois é um aspecto importante do processo de urbanização e redistribuição espacial da população no país, acredita-se que é necessário aprofundar-se mais na compreensão do papel desse tipo de cidade e seu real significado na dinâmica demográfica nacional. Nesse sentido, esse texto - mesmo 
que em caráter mais especulativo, adentra na discussão sobre as cidades médias e seu crescimento a luz da dinâmica demográfica.

Destaca-se que, por questões que serão explicitadas mais adiante, adotou-se nesse trabalho o termo "cidades de porte médio". É claro que nessa discussão uma das questões centrais seria o conceito de "cidade média" - Como definir? Seria a partir do tamanho da sua população? Ou também seria necessário levar em consideração sua função e posição na rede de cidades? Porém, como se verá, este trabalho apartou-se deste debate, não apenas por suas dificuldades, mas também para centrar-se em questões mais importantes do ponto de vista da análise demográfica.

Assim, a definição dos munícipios de porte médio seguiu os critérios do IBGE (IBGE, 2007), ou seja, aqueles com população entre 100 a 500 mil habitantes. A partir deste corte também foram definidas outras categorias como pequeno e grande porte. Mesmo considerando que um corte com base no tamanho populacional seja impreciso e até mesmo arbitrário, acredita-se que tal decisão não implica maiores dificuldades para uma análise como a aqui proposta.

No entanto, outro elemento é central para o argumento deste estudo: sendo este a necessidade de conhecer os contextos regionais onde estas cidades estão situadas. Por exemplo, o aludido "crescimento das cidades médias" (ou de médio porte como preferido) aparentemente se situa em contextos regionais e socioespaciais muito mais complexos, quando comparado com outras localizações -, como no caso do interior dos estados.

Assim, com base nestas considerações preliminares, o objetivo deste texto é compreender o papel das cidades de porte médio no processo de interiorização da população e da migração. Para tanto, este artigo está organizado em três partes: a primeira seção apresenta uma breve discussão sobre o processo de urbanização no Brasil, particularmente no que se refere à concentração populacional no país. Nesse sentido, além de considerar alguma bibliografia a respeito, faz-se também uma rápida análise do crescimento populacional a partir de categorias de municípios, segundo classes de população, bem como da distribuição das cidades de porte médio no território brasileiro, a fim de encontrar evidências sobre a existência (ou não) de concentração populacional, de uma "desconcentração concentrada", para mencionar apenas alguns dos assuntos que permeiam a temática. Da mesma forma, serão consideradas questões como o desenvolvimento de novas formas urbanas e sua relação com o transbordamento metropolitano e o crescimento das cidades médias. 
Na segunda seção, através de evidências empíricas retiradas dos Censos de 2000 e 2010, analisou-se o crescimento populacional e a migração ${ }^{1}$ para estes municípios segundo dois recortes espaciais:

- Municípios de porte grande, médio e pequeno localizados em regiões metropolitanas e aglomerados urbanos do Estado de São Paulo².

- Municípios de porte grande, médio e pequeno, não pertencentes a regiões metropolitanas e a aglomerados urbanos do Estado de São Paulo.

O uso desses dois recortes espaciais se justifica na presente análise em função do interesse em verificar a hipótese da interiorização para os municípios de porte médio ou de transbordamento metropolitano.

\section{A urbanização brasileira, concentração, desconcentração e crescimento das cidades $^{3}$ médias - um embate teórico.}

O ano de 2008 marcou a transição de uma população mundial rural para urbana. E, segundo as projeções, mais de $50 \%$ das pessoas passou a residir nestes espaços e o crescimento da população urbana responderá pela maior parte do incremento mundial nos próximos anos (UNFPA, 2007).

No Brasil e em outros países da América Latina, esse fenômeno não é recente, como a transição mundial, e data de meados da década de 1960. Nesse período, o crescimento populacional ainda era marcado por altas taxas de crescimento vegetativo, mas também por grandes fluxos migratórios do tipo rural-urbano. Foi no lapso de trinta anos que o país delineou sua transição urbana. A população urbana "em 1950 mal atingia a cifra de 18 milhões de habitantes, representando 36\% da população total, e atinge em 1980 a casa dos 80 milhões". Em trinta anos, o percentual da população urbanizada atingiu $68 \%$. Esse crescimento não foi somente marcado pela concentração populacional nos grandes centros; mas também apresentou duas vertentes principais. A primeira foi a concentração de um

\footnotetext{
${ }^{1}$ Para análise dos fluxos migratórios foram analisados apenas dados do censo de 2010. Porém, para o crescimento populacional foram utilizados os censos de 2000 e 2010.

${ }^{2}$ Quanto às regiões metropolitanas, foram consideradas as oficiais até 2014 (Região Metropolitana de São Paulo, Campinas, Santos, Vale do Paraíba e Litoral Norte e Sorocaba). Já os aglomerados urbanos foram considerados aqueles oficiais segundo o Censo de 2010 (Piracicaba e Jundiaí).

${ }^{3}$ Visando não retirar o foco do principal objetivo deste texto, estamos utilizando o termo "cidade" como sinônimo de "município" o que, sabemos, não é adequado, já que a primeira noção mereceria uma discussão mais aprofundada.
} 
grande contingente populacional em poucas metrópoles e a segunda foi um processo de redistribuição espacial da população em "cidades de diferentes tamanhos que se integram num complexo padrão de divisão territorial do trabalho social tanto entre o campo e a cidade como entre as cidades" (FARIA, 1991, p.103).

Em 1940, o grau da urbanização brasileira era de $26 \%$ e, em 1980, alcançou $68 \%$. São os dados do Censo de 1970 que revelam o ponto de inflexão do local de residência da população, em que ela passa de rural para urbana, tal como demonstra a Tabela 1. Em 2010, esse percentual foi de $84 \%$.

Tabela 1: População residente por situação de domicílio. Brasil, 1950/2010

\begin{tabular}{c|c|c|c|c|c|c|c}
\hline Ano & $\mathbf{1 9 5 0}$ & $\mathbf{1 9 6 0}$ & $\mathbf{1 9 7 0}$ & $\mathbf{1 9 8 0}$ & $\mathbf{1 9 9 1}$ & $\mathbf{2 0 0 0}$ & $\mathbf{2 0 1 0}$ \\
\hline Urbana & 18.782 .891 & 32.004 .817 & 52.904 .744 & 82.013 .375 & 110.875 .826 & 137.953 .959 & 160.925 .804 \\
Rural & 33.161 .506 & 38.987 .526 & 41.603 .829 & 39.137 .198 & 36.041 .633 & 31.845 .211 & 29.829 .995 \\
Total & 51.944 .397 & 70.992 .343 & 94.508 .573 & 121.150 .573 & 146.917 .459 & 169.799 .170 & 190.755 .799 \\
\hline \hline \multicolumn{7}{c}{ Distribuição percentual } \\
\hline \hline Urbana & 36,16 & 45,08 & 55,98 & 67,70 & 75,47 & 81,25 & 84,36 \\
Rural & 63,84 & 54,92 & 44,02 & 32,30 & 24,53 & 18,75 & 15,64 \\
\hline
\end{tabular}

Fonte: IBGE, Censos Demográficos de 1950/2010.

Nesse processo histórico de reorganização do espaço brasileiro, observou-se o aumento progressivo da população em cidades cada vez maiores. Em 1940, as cidades com menos de 20 mil pessoas concentravam 85\% da população, enquanto que em 1980 essa porcentagem cai para $46 \%$. Já os municípios com mais de 500 mil habitantes apresentaram crescimento no mesmo período, concentrando $8 \%$ da população em 1940, e 32\% em 1980 (MARTINE, 1994). No período de 1940 a 1980, os aglomerados metropolitanos foram os que mais cresceram, sendo receptores de grandes contingentes populacionais, principalmente a RMSP, que recebeu grandes fluxos migratórios, como os de nordestinos. Contudo, o Censo de 1991 demarca um arrefecimento no crescimento dos grandes centros (BAENINGER, 2011; BAENINGER e PEREZ 2011).

Para muitos autores, essa fase seria caracterizada pela chamada desmetropolização, e está atrelada ao processo de desconcentração industrial e de deseconomias de aglomeração ${ }^{4}$

4 Os grandes centros por muito tempo foram vantajosos para a concentração industrial, mas a elevada concentração passou a gerar custos e desvantagens para a localização de indústrias em certos centros urbanos, principalmente nas grandes metrópoles. Nesse processo de "deseconomia" ocorre a desconcentração industrial . 
(ARAUJO, MOURA e DIAS, 2011).

Matos (2000) destaca que a concentração econômica e demográfica pode ter chegado ao seu ponto de saturação na década de 1970, e que os períodos posteriores evidenciaram uma tendência de redistribuição espacial das atividades econômicas e da população. $\mathrm{O}$ autor aponta trabalhos como o de MARTINE e DINIZ (1989), AMARANTE e BONDIOLI (1987) e TOWNROE e KEEN (1984), que afirmam essa tendência de desconcentração populacional, principalmente no estado de São Paulo. Matos (2000) também cita os trabalhos de AZZONI (1986), HADDAD (1989) e DINIZ (1993), que desmitificam as generalizações no processo de desconcentração populacional e econômico.

Segundo Cunha (2003), os anos de 1980 demarcaram a transformação na dinâmica econômica, social e demográfica, com rebatimentos nos processos de redistribuição espacial da população, quando novas localidades e outros tipos de deslocamentos ganharam importância. Porém, para o autor, este processo de desconcentração populacional deve ser relativizado, pois está muito mais circunscrito às regiões metropolitanas de São Paulo e do Rio de Janeiro. E, mesmo aceitando essa desconcentração, deve-se salientar que não há um processo de equidade regional, pois as cidades pequenas continuam a perder população em favor das cidades maiores, o que mostra que os desequilíbrios regionais ainda permeiam a rede urbana:

O que se pretende mostrar, na verdade, é que a realidade da desconcentração metropolitana é apenas visível, e também relativa, no grande centro econômico e demográfico do país, representado pelos estados de São Paulo e Rio de Janeiro, fortemente afetados pela grave crise econômica que assolou o país nos anos 80. Uma das consequências foi a redução significativa do crescimento de suas áreas metropolitanas, em função de uma redução importante da imigração e também de um aumento da emigração intra e interestadual (CUNHA, 2003, p. 225).

Para Panizzi (1990), a involução metropolitana deve ser relativizada ao considerar dois fatores: primeiro, que as metrópoles brasileiras continuam influenciando o crescimento de muitos núcleos urbanos de porte médio ${ }^{5}$ em expansão. O que se constata é que a maioria desses municípios que estão em crescimento está localizada, em grande parte, em áreas metropolitanas ou próximos a elas, portanto, nos seus eixos de expansão. De acordo com

\footnotetext{
${ }^{5}$ Este trabalho distingue os termos cidades médias e cidades de porte médio. De acordo com Moura (2011) muitas análises sobre o processo de urbanização são feitas a partir de tipologias de cidades e muitas vezes segundo critérios de porte populacional. Porém, cabe salientar que nem sempre o porte populacional emana uma hierarquia urbana. Nesse sentido, cabe salientar que as cidades médias são aquelas que, além do porte populacional, possuem determinadas funções urbanas dentro do sistema de cidades, já as cidades de porte médio são aquelas com população entre 100 e 500 mil habitantes.
} 
Silva (2013), esse primeiro fator demonstra a ampliação do espaço de assentamento da metrópole, ou seja, o que ocorre é uma relação de complementariedade da metrópole com outras localidades, que muda de acordo com a escala regional:

Nessa ampliação do espaço de assentamento torna-se importante considerar uma articulação espacial que envolva diversas escalas, a expansão metropolitana evidencia a necessidade de ter uma perspectiva mais regional, já que a urbanização prossegue se expandindo para outras regiões do país, apresentando também características de metropolização. Processos como este podem ser apontados, como a integração urbana e econômica entre a RMSP e as quatro áreas urbanas industriais próximas, constituídas por Campinas, São José dos Campos, Sorocaba e Santos (SILVA, 2013, p.31).

O segundo ponto que é levado em consideração por Panizzi (1990), é que, em nível da rede urbana, as metrópoles brasileiras ainda são caracterizadas pela concentração das atividades econômicas mais modernas, da grande indústria, dos serviços especializados, dos negócios financeiros e dos meios de comunicação assentados nas tecnologias de ponta. Enfim, "permanecem sendo, nessas circunstâncias, o espaço privilegiado da produção do conhecimento técnico-científico e das instâncias de decisão política" (PANIZZI, 1990, p.51).

Portanto, as metrópoles continuam como o lócus, por excelência, das relações sociais e econômicas, e acompanham de perto as mudanças ocasionadas pelo processo de globalização e mundialização da economia, bem como as transformações tecnológicas do processo produtivo, que resultam em uma configuração territorial diferenciada. Esta configuração conjuga espaços marcados por elementos de modernização e outros de atraso. As metrópoles brasileiras configuram bem essa conformação e têm consequências difundidas em todo o seu sistema urbano, como destaca Panizzi (1990):

Contudo, o que se verifica é uma modificação do perfil de urbanização brasileira onde a rede urbana assume novos contornos marcados pelas diferenças inter-regionais, as cidades de porte médio têm o seu espaço redefinido pelo crescimento populacional e pela modificação dos processos socioeconômicos, e as metrópoles veem o seu papel e suas funções transformadas tanto ao nível da definição do sistema de cidades quanto ao nível da estrutura interna mantendo, porém, o seu papel de liderança (PANIZZI, 1990, p.52).

Enfatiza-se que mesmo com o processo de compressão espaço-tempo (HARVEY, 1992), consequência da nova ordem econômica e da difusão das tecnologias, a organização espacial e a localização das atividades nas aglomerações urbanas ainda possuem um sistema que demanda logística. Tais fenômenos afirmam a cidade de São Paulo como ponto central da rede urbana nacional, estando articulada com a rede mundial de cidades globais. Assim, 
dentro da chamada Macrometróple Paulista, observa-se uma efetiva tendência de desconcentração industrial, partindo da RMSP em direção aos polos adjacentes, que agora redefinem seus papéis dentro da rede urbana, e são caracterizados pelo crescimento de muitos municípios que, devido a este incremento, passaram para a categoria de núcleos urbanos de porte médio ${ }^{6}$ (ARAUJO, MOURA e DIAS, 2011).

Sobre a formação de cidades-regiões ou de novas morfologias urbanas como a Macrometrópole, Reis (2006) destaca que a formação destas está relacionada com processos anteriores. Para o autor, a periferização da metrópole no período fordista premeditou a produção de formas mais complexas. Porém, é necessário ressaltar que as lógicas de produção do novo espaço são estruturadas por outros condicionantes. Se antes o processo de industrialização ditava a concentração, hoje a reestruturação produtiva, a globalização e o capital imobiliário criam um tecido urbano concentrado e disperso.

Para muitos autores como Reis (2006), Stoper (1990), Castells (2012) e Ascher (1995), a constituição dos arranjos urbanos contemporâneos tem relação com o atual estágio do comércio mundial (globalização da economia e da produção) e flexibilização do trabalho e da produção. Para esses autores, essas condicionantes transformaram o modo de vida da população e ampliaram o modo de viver metropolitano e cosmopolita para outras áreas, bem como interligaram os espaços através da circulação, da mobilidade, da conectividade, das redes e do consumo.

Assim, o espaço urbano dos países periféricos e de grandes áreas como São Paulo, Buenos Aires e Santiago é caracterizado pela concentração em grandes centros, mas também pela formação e interligação de várias centralidades. $O$ espaço metropolitano agora se apresenta de maneira fragmentada pelo território, não mais conurbado, mas com espaços intersticiais com vazios, áreas rurais, cidades de diferentes tamanhos, funções e com vínculos estreitos entre si (REIS, 2006).

Segundo Ascher (1995), o processo de metropolização atual é caracterizado por uma mancha urbana que se expandiu de forma progressiva para as periferias e diminuiu a densidade urbana das aglomerações. Para o autor, ao mesmo tempo em que muitas áreas centrais e do interior da metrópole declinaram sua densidade, ocorreu o aumento da densidade

${ }^{6} \mathrm{O}$ estudo feito pelo NESUR-UNICAMP, IPEA e IBGE em 2001 conceitua as cidades médias como aquelas que possuem entre 100 a 500 mil habitantes. O Regic - Estudo de Regiões de Influências das Cidades - (2007) adota a mesma tipologia. Dos 5.565 mil municípios que compunham o território brasileiro em 2010, 245 eram considerados cidades de porte médio e concentravam $25 \%$ do total da população, sendo que $94 \%$ dessa população residiam em áreas urbanas. 
nas áreas periféricas e também a articulação com aglomerados urbanos afastados. Esta interligação entre as áreas é o prenúncio de novas morfologias urbanas.

Davidovich (2004), em seu artigo "A volta para metrópole", debate o tema da reconcentração populacional e econômica nas áreas metropolitanas a partir dos anos de 1990. Nele, a autora sinaliza a importância de analisar o processo de reconcentração sobre outra ótica, uma vez que a forma urbana da metrópole não condiz mais com estrutura tradicional de uma região conurbada e concentrada. Para autora, surge no período atual formas de concentração populacional variadas, tais como as cidades-regiões, as regiões metropolitanas institucionalizadas, os aglomerados não-metropolitanos, entre outros.

Este trabalho partilha com esta visão, portanto, para além de uma desconcentração ou de uma desmetropolização - o que se observa através dos novos processos de redistribuição espacial da população é a formação de arranjos espaciais mais complexos Nesse sentido, sinaliza-se a importância de analisar o crescimento demográfico das cidades de porte médio através de outras perspectivas: através da análise do contexto regional e socioespacial.

\section{O fenômeno do surgimento das cidades médias: o caso de São Paulo}

\section{A situação no país: aspectos gerais}

N Brasil, o surgimento e a importância cada vez maior dos municípios de porte médio são inegáveis, principalmente até a década de 1980. A Tabela 2 mostra a evolução dos municípios por categorias de população residente. Percebe-se que de 1970 a 2010 o número de núcleos urbanos quase triplicou no país, porém foram os municípios de porte grande que apresentaram maior crescimento, tanto em termos de unidade quanto população.

Ainda se observa através desta tabela que grande parte da população brasileira reside em cidades com menos de 100 mil habitantes, porém seu peso relativo na concentração populacional vem declinando, se em 1970 estes munícipios concentravam 66\% da população, em 2010 passaram a concentrar 45\%, já as cidades com mais de 500 mil habitantes passaram de $19 \%$ para $29 \%$ - enquanto que os de porte médio variaram entre $15 \%$ e $25 \%$. 
Tabela 2: Número de municípios por classes de população. Brasil 1950/2010.

\begin{tabular}{c|ccccc}
\hline \hline \multirow{2}{*}{ Categorias de município } & \multicolumn{5}{|c}{ Classe de população } \\
\cline { 2 - 6 } & $\mathbf{1 9 7 0}$ & $\mathbf{1 9 8 0}$ & $\mathbf{1 9 9 1}$ & $\mathbf{2 0 0 0}$ & $\mathbf{2 0 1 0}$ \\
\hline Abaixo de 100.000 & 3858 & 3849 & 4304 & 5283 & 5282 \\
De 100.001 a 500.000 & 83 & 124 & 162 & 193 & 245 \\
Mais de 500.000 & 11 & 18 & 25 & 31 & 38 \\
\hline Total & 3952 & 3991 & 4491 & 5507 & 5565 \\
\hline Categorias de município & \multicolumn{5}{c}{ População Residente } \\
\hline Abaixo de 100.000 & 61.915 .394 & 67.989 .605 & 76.067 .276 & 83.131 .556 & 86.319 .122 \\
De 100.001 a 500.000 & 14.610 .868 & 23.631 .329 & 32.073 .626 & 39.576 .864 & 48.565 .171 \\
Mais de 500.000 & 17.982 .321 & 29.529 .639 & 38.776 .557 & 46.882 .273 & 55.871 .506 \\
\hline Total & 94.508 .583 & 121.150 .573 & 146.917 .459 & 169.590 .693 & 190.755 .799 \\
\hline \hline
\end{tabular}

Fonte: IBGE, Censos Demográficos de 1970/2010.

Contudo, nota-se que o crescimento das cidades médias foi significativo, e seu estudo merece uma reflexão cuidadosa. Nesse sentido, a questão que se levanta neste trabalho é: como interpretar o crescimento das cidades de porte médio, tanto em número quanto em concentração de população, em tempos de "expansão metropolitana" e de formação de novas morfologias urbanas? É possível dizer que tal crescimento representa uma "real ascensão" deste tipo de cidade, particularmente no interior dos estados? Ou tal interpretação seria falaciosa na medida em que estaríamos apenas observando o crescimento de cidades em contextos metropolitanos ou de aglomerações urbanas, ou seja, seriam muito mais um retrato da expansão destas áreas?

Assim este trabalho, ao "localizar" estas cidades e seus contextos regionais, pretende debater o significado de ser uma cidade desta categoria dentro de uma região metropolitana ou de um aglomerado urbano e fora destes. Nesse sentido, investiga-se se este fenômeno refletiria, por exemplo, o crescimento destas dentro do perímetro da chamada "desconcentração concentrada".

Através do Mapa 1, observa-se que grande parte das cidades de porte médio estão localizadas na região Sudeste - principalmente no estado de São Paulo (dos 193 municípios classificados como médios em 2000, 54 deles estavam localizados no estado de São Paulo). 
Mapa 1: Distribuição dos municípios brasileiros por classe de população. Brasil, 2000 e 2010.

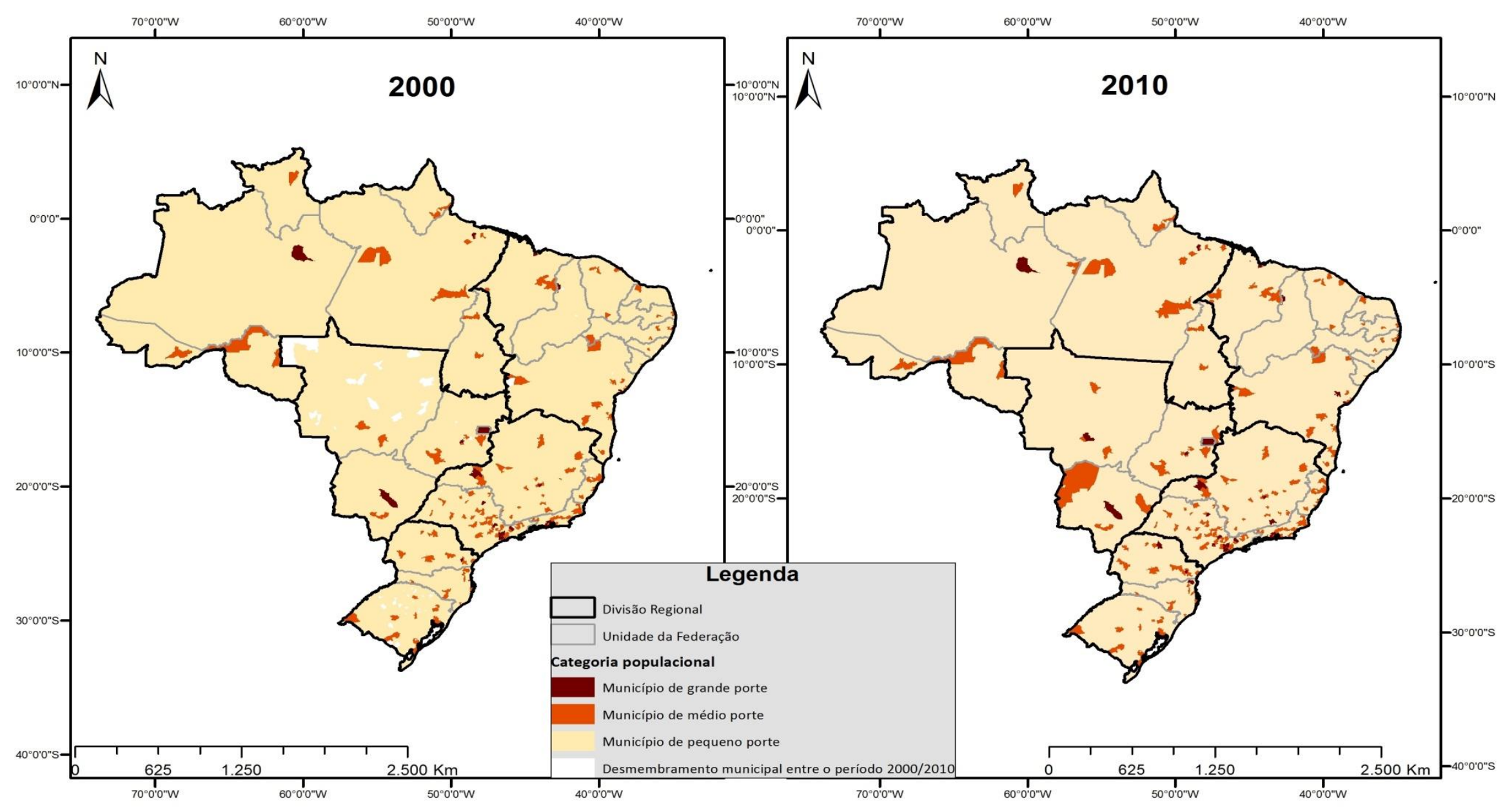

Fonte: IBGE: Censos Demográficos 2000 e 2010 (Malha digital dos municípios). 
O caso do surgimento e expansão das cidades médias é particularmente significativo no caso do Estado de São Paulo. Apesar de localizado no perímetro do "desenvolvimento poligonal" (DINIZ, 1993) ou na região da "desconcentração concentrada" delimitada em escala mais agregada (a interestadual), não há dúvidas de que a realidade paulista também guarda características que permitiriam discutir o tema da desconcentração/desconcentração concentrada (Cano, 1997) no que se refere às suas regiões que, como se pode mostrar, tendem concentrar grande parte dos municípios brasileiros de porte médio.

Assim, embora se tenha consciência de que os resultados encontrados neste estudo não necessariamente poderão ser expandidos para todo o país, tem-se alguma segurança de que o caso de São Paulo, particularmente porque juntamente com o Rio de Janeiro são os estados que mais “interiorizaram” suas populações, será uma excelente referência para apurar o papel das cidades medias no processo de redistribuição espacial da população no Brasil.

\section{Interiorização das cidades médias ou expansão metropolitana}

Como referido anteriormente, um dos objetivos deste trabalho, é analisar o quanto o crescimento do número e o peso demográfico das cidades de porte médio paulistas respondem ao processo de interiorização e, portanto, por uma real desconcentração populacional. Contudo, a análise também mostrará que esta questão, embora observável, não responde pelos grandes movimentos demográficos representados por estas cidades que, na verdade, encontram-se em boa medida localizadas nos contextos da expansão metropolitana. Para tanto, os dados analisados correspondem ao crescimento dessas cidades localizadas fora e dentro das regiões metropolitanas e aglomerados urbanos no estado de São Paulo.

Assim, a Tabelas 3 apresenta o número de municípios por classe de população, a população residente e as taxas de crescimento para os anos 2000 e 2010 no estado de São Paulo. Destaca-se também que esta tabela apresenta os municípios que mudaram de categoria populacional entre 2000 e 2010. Esta decisão metodológica é importante na medida em que permite que se tenha uma visão mais clara das trajetórias dos municípios, em termos das categorias de porte, ao longo do período observado. 
Tabela 3: Número de municípios, população residente, crescimento absoluto e taxa de crescimento populacional por classe de população. São Paulo 2000 e 2010.

\begin{tabular}{|c|c|c|c|c|c|c|}
\hline & Categoria (*) & $\begin{array}{c}\text { Número de } \\
\text { centros urbanos }\end{array}$ & \begin{tabular}{|} 
População em \\
2000
\end{tabular} & $\begin{array}{l}\text { População } \\
\text { em } 2010\end{array}$ & $\begin{array}{c}\text { Crescimento } \\
\text { Absoluto }\end{array}$ & $\begin{array}{c}\text { Taxa de } \\
\text { Crescimento }\end{array}$ \\
\hline \multirow{2}{*}{$\begin{array}{l}\text { Grande } \\
\text { Porte }\end{array}$} & $\begin{array}{c}\text { Municípios com mais de } 500 \\
\text { mil habitantes }\end{array}$ & 8 & 15.525 .702 & 16.898 .808 & 1.373 .106 & 0,85 \\
\hline & $\begin{array}{c}\text { Novos municípios com mais } \\
\text { de } 500 \text { mil habitantes em } 2010\end{array}$ & 1 & 493.468 & 586.625 & 93.157 & 1,74 \\
\hline \multirow{3}{*}{$\begin{array}{l}\text { Médio } \\
\text { Porte }\end{array}$} & $\begin{array}{c}\text { Municípios com população } \\
\text { entre } 100 \text { e } 500 \text { mil habitantes }\end{array}$ & 53 & 10.502 .671 & 11.955 .724 & 1.453 .053 & 1,30 \\
\hline & $\begin{array}{c}\text { Novos Municípios com } \\
\text { população entre } 100 \text { e } 500 \text { mil } \\
\text { habitantes }\end{array}$ & 13 & 1.180 .311 & 1.382 .851 & 202.540 & 1,60 \\
\hline & $\begin{array}{c}\text { Municípios com menos de } 100 \\
\text { mil habitantes }\end{array}$ & 570 & 9.334 .468 & 10.438 .191 & 1.103 .723 & 1,12 \\
\hline \multicolumn{2}{|r|}{ Total } & 645 & 37.036 .620 & 41.262.199 & 4.225.579 & 1,09 \\
\hline
\end{tabular}

(*) foram considerados médios apenas aqueles municípios que não mudaram de categorias nos dois momentos censitários. Para contemplar a totalidade dos municípios a tabela cria duas outras categorias que correspondem aos que mudaram de tamanho no período.

Fonte: IBGE: Censos Demográficos 2000 e 2010

Nota-se, através da Tabela 3, que a maioria da população do estado de São Paulo está localizada em cidades com mais de 500 mil habitantes (41\% no Censo de 2000 e $40 \%$ no Censo de 2010), distribuída em um total de oito municípios pertencentes a esta categoria. Contudo, observa-se que estes municípios foram os que apresentaram um crescimento geométrico abaixo da média do estado entre o período 2000/2010 (0,85\% a.a.). Já aquelas que se transformaram em porte grande, ou seja, passaram da categoria de médio para grande porte, apresentaram uma taxa de crescimento de $1,74 \%$ a.a. contra uma taxa para os municípios médios de $1.30 \%$ a.a. Visto desta forma, pode-se perceber que, de fato, são os municípios médios os que mais crescem no período, mesmo quando este se torna grande no momento final da observação.

Embora o dado não conste na tabulação apresentada não é difícil deduzir a partir destas informações que nos anos 2000, as cidades médias ganharam peso relativo na população total do estado, muito embora também seja claro que tal ganho foi pouco expressivo, já que de $28 \%$ em 2000 passam a responder por cerca de $28,8 \%$ da população estadual em 2010; se a estes acrescentamos o único município que mudou de faixa, ainda assim a variação seria muito baixa (de $29,7 \%$ para $30,3 \%$ ). 
Portanto, de fato se observa um crescimento no número e na população dos municípios de porte médio no estado de São Paulo. Porém, destaca-se que sua participação tanto no número de cidades, quanto na população total do estado é ainda muito pequena.

Contudo, uma face importante deste trabalho se desprende da análise dos dados que geraram o Mapa 2. Nessa figura é perceptível, por um lado, que a grande maioria dos municípios paulistas, ou seja, aqueles que possuem menos de 100 mil habitantes se encontram localizados fora das áreas metropolitanas. Por outro lado, constata-se que os municípios de porte médio e grande (45 cidades em 2000 e 56 em 2010) localizavam-se em sua maioria em regiões metropolitanas e aglomerados urbanos, especialmente nas RM de São Paulo, Campinas, Vale do Paraíba e Litoral Norte e Baixada Santista e a mais recentemente criada, Sorocaba e nas aglomerações de Piracicaba e Jundiaí. Nota-se, através da Tabela 4, que a maioria dos munícipios que mudaram para categoria de porte médio no período 2000/2010 também estavam localizados nessas áreas.

Mapa 2: Distribuição dos municípios do estado de São Paulo segundo classe de população. São Paulo, 2000 e 2010.

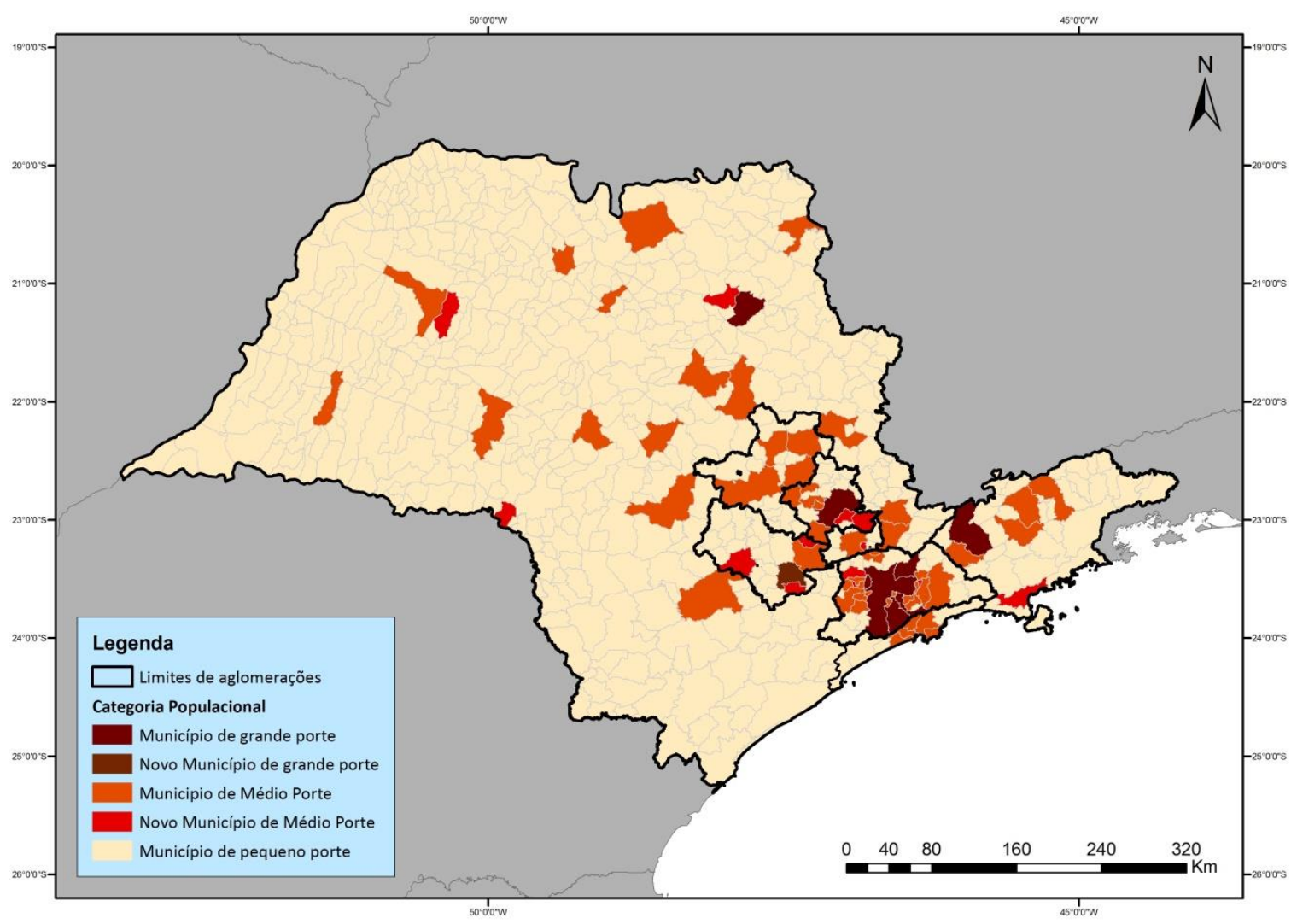

Fonte: IBGE: Censos Demográficos 2000 e 2010 (Malha digital dos municípios). 
Tabela 4: Número de municípios, população residente, crescimento absoluto e taxa de crescimento populacional por classe de população, localizados em regiões metropolitanas e em outras áreas do estado de São Paulo - São Paulo 2000 e 2010.

\begin{tabular}{|c|c|c|c|c|c|c|c|c|c|c|c|}
\hline & \multirow[b]{2}{*}{ Categoria $(*)$} & \multicolumn{2}{|c|}{$\begin{array}{c}\text { Número de centros } \\
\text { urbanos }\end{array}$} & \multicolumn{2}{|c|}{ População em 2000} & \multicolumn{2}{|c|}{ População em 2010} & \multicolumn{2}{|c|}{ Crescimento Absoluto } & \multicolumn{2}{|c|}{ Taxa de Crescimento } \\
\hline & & $\begin{array}{l}\text { Em regiões } \\
\text { metropolitanas }\end{array}$ & $\begin{array}{c}\text { Em outras } \\
\text { áreas do } \\
\text { Estado }\end{array}$ & $\begin{array}{c}\text { Em regiões } \\
\text { metropolitanas }\end{array}$ & $\begin{array}{l}\text { Em outras } \\
\text { áreas do } \\
\text { Estado }\end{array}$ & $\begin{array}{l}\text { Em regiões } \\
\text { metropolitanas }\end{array}$ & $\begin{array}{c}\text { Em outras } \\
\text { áreas do } \\
\text { Estado }\end{array}$ & $\begin{array}{l}\text { Em regiões } \\
\text { metropolitanas }\end{array}$ & $\begin{array}{c}\text { Em outras } \\
\text { áreas do } \\
\text { Estado }\end{array}$ & $\begin{array}{l}\text { Em regiões } \\
\text { metropolitanas }\end{array}$ & $\begin{array}{c}\text { Em outras } \\
\text { áreas do } \\
\text { Estado }\end{array}$ \\
\hline \multirow{2}{*}{$\begin{array}{l}\text { Grande } \\
\text { Porte }\end{array}$} & $\begin{array}{c}\text { Municípios com mais de } 500 \\
\text { mil habitantes }\end{array}$ & 7 & 1 & 15.020 .779 & 504.923 & 16.294 .126 & 604.682 & 1.273 .347 & 99.759 & 0,82 & 1,82 \\
\hline & $\begin{array}{c}\text { Novos municípios com mais } \\
\text { de } 500 \text { mil habitantes em } \\
2010\end{array}$ & 1 & - & 493.468 & - & 586.625 & - & 93.157 & - & 1,74 & - \\
\hline \multirow{2}{*}{$\begin{array}{l}\text { Médio } \\
\text { Porte }\end{array}$} & $\begin{array}{c}\text { Municípios com população } \\
\text { entre } 100 \text { e } 500 \text { mil habitantes }\end{array}$ & 38 & 16 & 7.743 .363 & 2.759 .308 & 8.810 .085 & 3.145 .639 & 1.066 .722 & 386.331 & 1,30 & 1,32 \\
\hline & $\begin{array}{c}\text { Novos Municípios com } \\
\text { população entre } 100 \text { e } 500 \\
\text { mil habitantes }\end{array}$ & 9 & 3 & 907.113 & 273.198 & 1.061 .014 & 321.837 & 153.901 & 48.639 & 1,58 & 1,65 \\
\hline $\begin{array}{l}\text { Pequeno } \\
\text { Porte }\end{array}$ & $\begin{array}{l}\text { Municípios com menos de } \\
100 \text { mil habitantes }\end{array}$ & 117 & 466 & 3.022 .102 & 6.312 .366 & 3.402 .526 & 7.035 .665 & 380.424 & 723.299 & 1,19 & 1,09 \\
\hline & Total & 172 & 486 & 27.186.825 & 9.849 .795 & 30.154.376 & 11.107 .823 & 2.967.551 & 1.258 .028 & 1,04 & 1,21 \\
\hline
\end{tabular}

(*) foram considerados médios apenas aqueles municípios que não mudaram de categorias nos dois momentos censitários. Para contemplar a totalidade dos municípios a tabela cria duas outras categorias que correspondem aos que mudaram de tamanho no período.

Fonte: IBGE: Censos Demográficos 2000 e 2010 
Porém, para além da concentração dos municípios de porte médio em regiões metropolitanas e fora delas, é necessário analisar o crescimento populacional dessas cidades nessas duas grandes zonas. Um primeiro resultado que chama a atenção é que, embora pequena, existe uma diferença entre as taxas de crescimento populacional para as cidades médias localizados em RMs e AUs e no restante do estado em favor das primeiras (Tabela 4). Nota-se também que o crescimento absoluto destes foi mais expressivo nos municípios localizados em áreas metropolitanas, não obstante não se possa perder de vista que mais da metade desses municípios estavam localizados nessas áreas. O Mapa 3 apresenta as taxas de crescimento populacional dos municípios que eram considerados médios em 2000 para o período 2000/2010.

Mapa 3 : Taxa média geométrica de crescimento anual da população residente em municípios de porte médio, localizados em regiões metropolitanas e fora delas no São Paulo entre o período de 2000/2010.

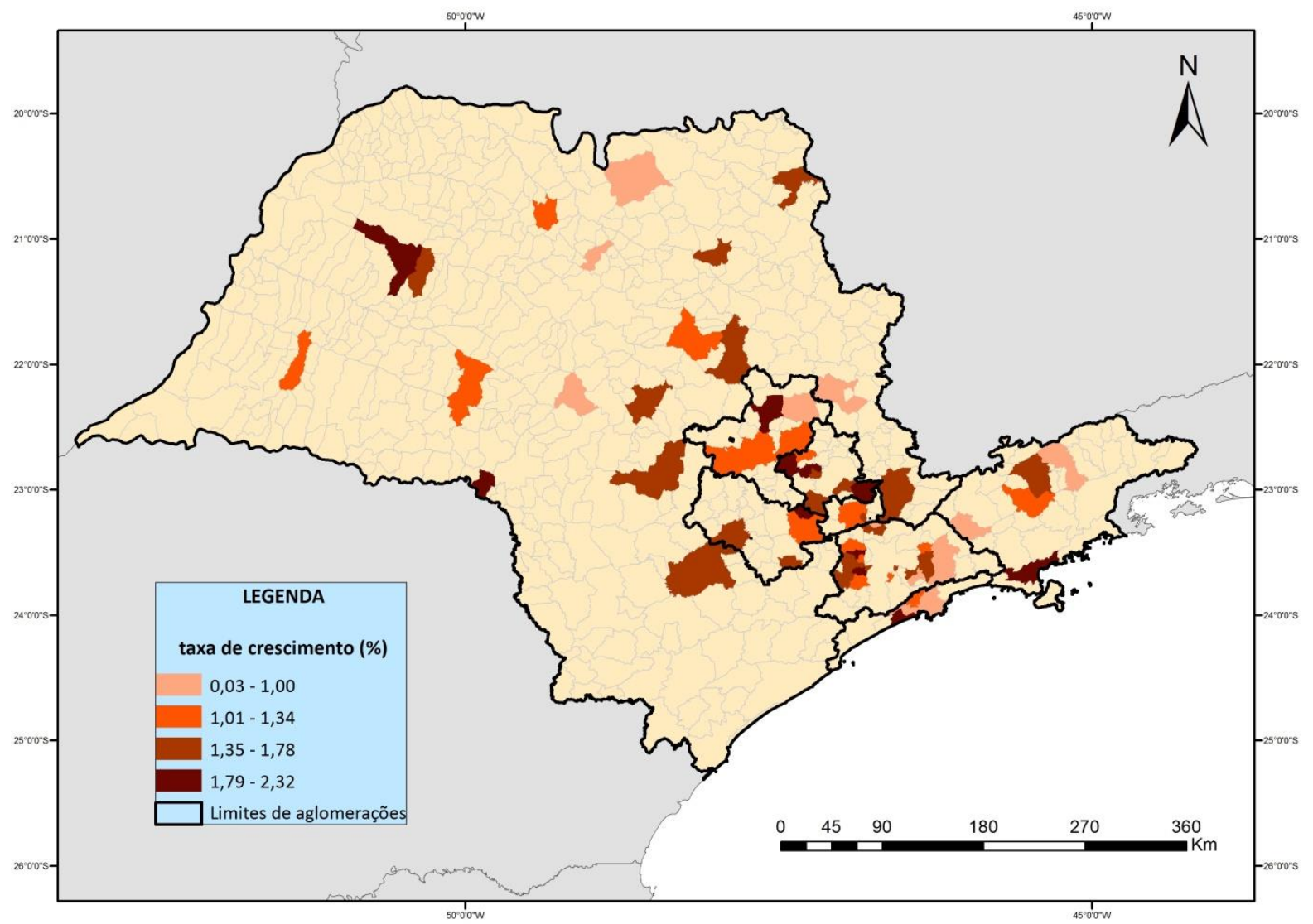

Fonte: IBGE - Censos Demográficos 2000 e 2010 (Malha digital dos municípios).

Os dados ainda permitem constatar o aumento considerável das cidades de porte populacional médio localizadas em regiões metropolitanas e aglomerados urbanos (de 38 para 
47 - Tabela 4), enquanto que aquelas não localizados nestas regiões passaram de 16 para 19. Esse vertiginoso crescimento nas áreas metropolitanas, aliado ao crescimento populacional superior às outras categorias, é um indicativo - e talvez um resultado inquestionável - de que o crescimento destes municípios representa muito mais uma expansão do espaço metropolitano, tal qual aponta Panizzi (1990), do que uma interiorização ou uma desconcentração populacional.

Outro fenômeno demográfico utilizado neste trabalho para analisar o papel das cidades médias no processo de redistribuição e possível interiorização da população foi à migração. É desnecessário justificar a inclusão desta variável tendo em vista o seu importante papel no processo de formação das grandes regiões metropolitanas no Brasil e, portanto, por sua influência na concentração populacional observada no país.

Na verdade, a despeito de tal importância o que mais interessa é mostrar aqui é que, novamente, pensar em um processo de interiorização da migração em função da sua maior concentração nas cidades de médio porte seria, para dizer o mínimo, exagerado. $\mathrm{O}$ que mostramos a continuação é que, não obstante o importante papel desta categoria de cidade tanto com área receptora, quanto expulsora de população, não há indícios suficientes, ao menos em São Paulo, de que o interior e as cidades desta categoria aí localizadas estejam respondendo por uma mudança importante do direcionamento dos fluxos migratórios internos.

O Gráfico 1 mostra a distribuição percentual da imigração e emigração de "data-fixa" ocorrida no estado de São Paulo segundo o porte populacional dos municípios. Percebe-se, através dele que $43 \%$ da imigração intraestadual apresentava como destino os municípios de médio porte, percentual bem maior que os $20 \%$ apresentado pelas cidades de grande porte. Em contrapartida, grande parte da emigração entre o período 2005/2010 ocorreu nos municípios de maior porte (quase 40\%), enquanto que a evasão nos municípios de porte médio foi de apenas $27 \%$. Ou seja, apenas com base na migração intraestadual fica muito evidente que as cidades médias são receptoras "liquidas" de migrantes.

\footnotetext{
${ }^{7} \mathrm{O}$ migrante de data-fixa seria aquele que há cinco anos antes da data de referência do censo, morava em um município diferente do qual foi recenseado.
} 
Gráfico 1: Distribuição percentual da imigração e emigração de "data-fixa" intraestadual, por classe de população. São Paulo, 2005/2010 .
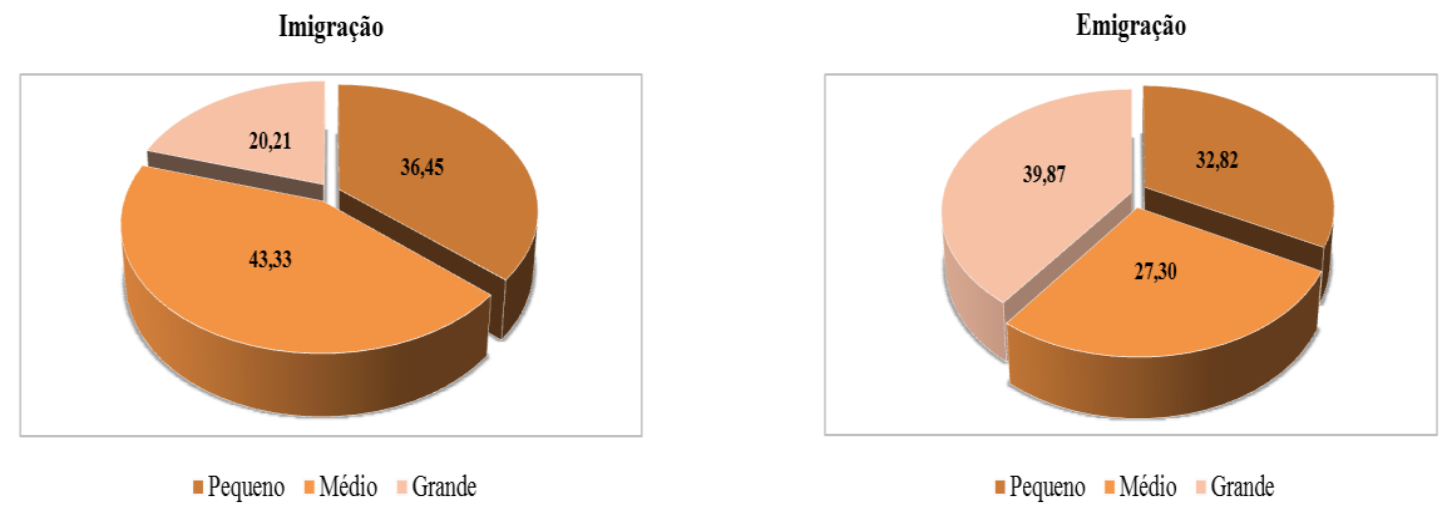

Fonte: IBGE - Censo Demográfico de 2010

Portanto, não há dúvidas que os dados do Gráfico 1 sugerem estar ocorrendo uma desconcentração populacional, com perda migratória nos municípios de porte grande em relação aos médios. Porém, ao analisar o Gráfico 2, que compara o percentual da imigração e emigração nos municípios pertencentes ou não a regiões metropolitanas e aglomerados urbanos, nota-se que grande parte da imigração intraestadual que ocorre nas aglomerações se dá nas cidades médias, o que não se observar no caso das cidades localizadas fora delas.

No caso da emigração, o mesmo gráfico mostra que 54\% desta ocorre em cidades grandes localizadas em áreas metropolitanas (ou aglomerados urbanos). Porém, ao observar a outra espacialidade, percebe-se que $77 \%$ da emigração dos municípios não metropolitanos estavam circunscritas aos municípios de menor porte.

Assim com base nestes dados sobre o destino e origem da migração, a hipótese de que o crescimento das cidades médias no estado de São Paulo faz parte de processos de expansão metropolitana, ou de formação de novas morfologias urbanas, fica claramente respaldada, em detrimento de uma possível interiorização da migração para outras áreas do estado.

\footnotetext{
${ }^{8}$ A distribuição percentual apresentada foi calculada com bases nas matrizes apresentadas nas tabelas 5 e 6 .
} 
Gráfico 2: Distribuição percentual da imigração e imigração de "data-fixa" intraestadual por classe de população, localizados em regiões metropolitanas e fora delas. São Paulo, 2005/2010.

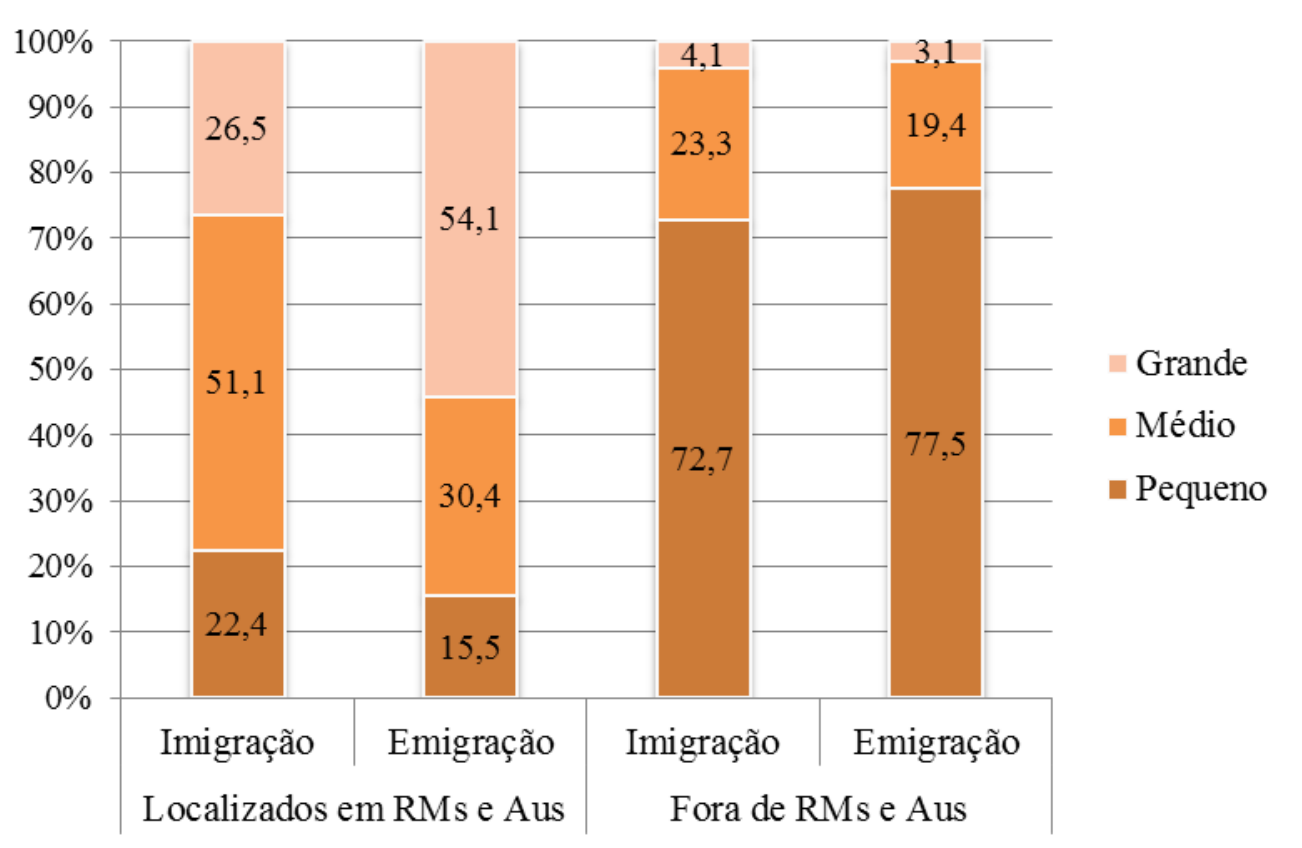

Fonte: IBGE - Censo Demográfico de 2010

Os dados demonstrados até aqui levam a uma reflexão sobre o processo de desconcentração da população para as cidades médias. De fato, pode-se pensar em uma interiorização de uma parcela da população rumo ao chamado "interior". Porém, ao analisar as Tabelas 5 e 6, percebe que do total de fluxos migratórios ocorridos no estado de São Paulo $69 \%$ acontecem nas regiões metropolitanas e aglomerados urbanos. Ou seja, os ditos fluxos “capital-interior" certamente envolvem à mobilidade originada na RMSP em direção à RMC, RMBS etc. Nesse sentido, a reflexão feita é: como pensar nesse processo de interiorização quando os fluxos ocorridos envolvem regiões que autores como LENCIONI (2011), MOURA (2009), DAVIDOVICH (2004), REIS (2006) entre outros citam como área de expansão do espaço de vida da metrópole.

Como já detalhado anteriormente, observa-se, através da Tabela 5, que a maior parte da imigração recebida pelos municípios localizados em regiões metropolitanas dirige-se às cidades médias, cerca de $51 \%$. Porém, percebe-se que os fluxos mais expressivos se originam nos municípios de grande porte. Em contrapartida, a Tabela 6 demonstra que grande parte das trocas migratórias realizadas nas áreas não metropolitanas ocorre entre municípios de pequeno porte. Apenas $23 \%$ dos fluxos migratórios que acontecem em áreas não metropolitanas se 
direcionam para as cidades de porte médio. Tais constatações reafirmam a tese de transbordamento metropolitano em detrimento de uma interiorização da migração.

Tabela 5: Fluxo de origem e destino de cidades localizadas em Regiões Metropolitanas ou Aglomerados Urbanos do estado de São Paulo segundo porte populacional. São Paulo, 2005/2010.

\begin{tabular}{c|cccc|c}
\hline \multirow{2}{*}{ Região em 2005 } & \multicolumn{4}{|c|}{ Região em 2010 } & \\
\cline { 2 - 5 } & Pequeno porte & Médio porte Grande porte & $\begin{array}{c}\text { Não pertence a } \\
\text { áreasde RM } \\
\text { ou AU de SP }\end{array}$ & Total \\
\hline Pequeno porte & 52.902 & 69.976 & 38.824 & 27.772 & 189.474 \\
Médio porte & 70.536 & 160.060 & 86.701 & 56.204 & 373.501 \\
Grande porte & 110.548 & 303.724 & 150.965 & 133.316 & 698.553 \\
Não pertence a áreas de RM ou AU de SP & 31.011 & 57.744 & 63.252 & 406.189 & 558.196 \\
Outras UFs & 89.468 & 227.487 & 436.975 & 239.406 & 993.336 \\
\hline Total & 354.465 & 818.991 & 776.717 & 862.886 & $\mathbf{2 . 8 1 3 . 0 6 0}$ \\
\hline \hline
\end{tabular}

Fonte: IBGE - Censo Demográfico de 2010

$\mathrm{Na}$ verdade, os dados até aqui analisados dizem respeito apenas à migração intraestadual o que poderia levar o leitor a pensar que a situação poderia ser distinta caso fossem considerados os dados da migração interestadual. Uma forma simplifica de esclarecer esta questão é a organização dos dados como apresentados nas Tabelas 5 e 6 . Percebe-se que a maioria dos fluxos interestaduais se direcionam as regiões metropolitanas, e principalmente as cidades de grande porte (57\%). Apenas 30\% dos fluxos interestaduais em direção as regiões metropolitanas tem como destino as cidades médias.

Tabela 6: Fluxo de origem e destino de cidades não localizadas em RMs ou Aus do estado de São Paulo segundo porte populacional. São Paulo, 2005/2010.

\begin{tabular}{|c|c|c|c|c|c|}
\hline \multirow[b]{2}{*}{ Região em 2005} & \multicolumn{4}{|c|}{ Região em 2010} & \multirow[b]{2}{*}{ Total } \\
\hline & Pequeno porte & Médio porte & Grande porte & $\begin{array}{c}\text { Pertence a áreas } \\
\text { de } R M \text { ou } \mathrm{AU} \\
\text { de SP } \\
\end{array}$ & \\
\hline Pequeno porte & 228.211 & 73.686 & 12.011 & 91.791 & 405.699 \\
\hline Médio porte & 56.635 & 17.330 & 4.389 & 46.413 & 124.768 \\
\hline Grande porte & 9.421 & 3.163 & & 6.590 & 19.174 \\
\hline Pertence a áreas de RM ou AU de SP & 139.802 & 68.916 & 9.915 & 1.051 .448 & 1.270 .082 \\
\hline Outras UFs & 160.179 & 59.197 & 20.029 & 753.931 & 993.336 \\
\hline Total & 594.249 & 222.292 & 46.345 & 1.950 .173 & 2.813 .060 \\
\hline
\end{tabular}

Fonte: IBGE - Censo Demográfico de 2010 
Davidovich (2004) afirma que, após os anos de 1990, as metrópoles passaram a se desenvolver em áreas contíguas, fora dos seus limites oficiais e seu entorno passou a abrigar uma migração de pessoas e indústrias. Nesse sentido, o trabalho de SILVA, CUNHA e ORTEGA (2015) demonstrou que a maior parte dos fluxos migratórios do estado de São Paulo ocorre dentro da chamada Macrometrópole Paulista, denotando uma relação complementariedade entre as localidades que formam a região. Destaca-se que as regiões metropolitanas e os aglomerados urbanos delimitados neste trabalho justamente fazem parte deste complexo metropolitano.

\section{Considerações Finais}

Assim, observou-se nesses cinquenta anos de urbanização brasileira não apenas o esvaziamento do campo, particularmente nas regiões sudeste, sul e nordeste, mas também a grande concentração da população nas grandes cidades. Ainda que mais recentemente existam aqueles que pregam certa desconcentração demográfica rumo ao interior e às cidades médias, não há dúvidas de que se esse processo existe, ele é muito tímido e, portanto, relativo, já que as grandes cidades e, sobretudo as regiões metropolitanas mantiveram (e em alguns casos até ampliaram) o peso relativo na população nacional e de seus respectivos estados (CUNHA, 2014).

Portanto, através deste trabalho, buscou-se compreender o significado da desconcentração populacional rumo às cidades de porte médio através da comparação de variáveis demográficas (migração e crescimento populacional) em duas espacialidades (Regiões Metropolitanas e Aglomerados Urbanos). Constatou-se que as maiores taxas de crescimento populacional e os fluxos migratórios mais expressivos ocorreram em direção às cidades médias localizadas em RMs e AUs (em síntese na Macrometrópole Paulista), o que leva a uma relativização do processo de desconcentração e interiorização no estado de São Paulo. 
AMARANTE, Luis A., BONDIOLI, Paulo. A apropriação regional da renda nacional no Brasil; 1975-85. NDRADE, T. A.

ANDRADE, T. A.. As cidades médias e a política nacional de desenvolvimento Urbano. Rio de Janeiro: Instituto de Pesquisa Econômica Aplicada (Ipea)/ Institutos de Pesquisas (Inpes), 1976.

ANDRADE, T. A.; LODDER, C. A. Sistema urbano e cidades médias no Brasil. Rio de Janeiro: IPEA/INPES, 1979.

ARAUJO, M. MOURA, R. DIAS, P. Cidades médias uma categoria em discussão. In: PEREIRA, R. H. M. (Org.); FURTADO, B. A. (Org.). Dinâmica Urbano-Regional: rede urbana e suas interfaces. 1. ed. Brasília: Ipea, 2011. v.1. 490p

ASCHER, François. Métapolis ou l'avenir des villes. Paris, França: Odile Jacob, 1995.

AZZONI, C. R. Indústria e reversão da polarização no Brasil, São Paulo, IPE/USP, 1986.

BAENINGER, R. Migrações internas no Brasil século 21: evidências empíricas e desafios conceituais. In: CUNHA, J. P (Org). Mobilidade espacial da população: desafios teóricos e metodológicos para o seu estudo. Campinas: Núcleo de Estudos de População Nepo/Unicamp, 2011.

BAENINGER, R. PEREZ, R. Metrópoles Brasileiras No Século 21: Evidências do Censo Demográfico de 2010. In: Anais: VII ENCONTRO NACIONAL SOBRE MIGRAÇÕES. Curitiba, 2011 - CD-ROOM.

Baeninger, R. Fases e faces da migração em São Paulo. 1. ed. Campinas, SP: Núcleo de Estudos de População, 2012. v. 1. 152p .

CANO, W. Concentração e desconcentração econômica regional no Brasil: 1970/95. Economia e Sociedade, Campinas, n.8, p.101-141, jun. 1997.

CASTELLS, Manuel. A Sociedade em Rede. 6a edição atualizada com novo prefácio, São Paulo: Paz e Terra, 2012

CUNHA, J. M. P.Redistribuição espacial da população: tendências e trajetória. São Paulo em Perspectiva, São Paulo: SEADE, v.17, n.3/4, p.218-233, jul./dez. 2003.

Dinâmica demográfica, migração e projeções populacionais da Macrometrópole Paulista. Relatório de pesquisa de apoio à elaboração do Plano de Ação da Macrometrópole Paulista (PAM). NEPO-UNICAMP/FUNDAP/EMPLASA. São Paulo, 2014.

DINIZ, C.C. Desenvolvimento poligonal no Brasil; nem desconcentração, nem contínua polarização. 
Belo Horizonte, NOVA ECONOMIA (Revista do Departamento de Ciências Econômicas da UFMG).

V.31. N.11. Set. 1993.

FAISSOL, S. O espaço, território, sociedade e desenvolvimento brasileiro. IN: FUNDAÇÃO INSTITUTO BRASILEIRO DE GEOGRAFIA - IBGE, Rio de Janeiro, 1994.

d

FARIA, V. Cinquenta anos de urbanização no Brasil. São Paulo: Revista Novos Estudos CEBRAP, n.29, p. 98-119, 1991.

HADDAD, Paulo. Economia Regional; teorias e métodos de análise. Fortaleza: Banco do Nordeste do

Brasil, 1989.

HARVEY, D. Condição pós-moderna. São Paulo: Loyola, 1992.

LENCIONI, S. 2011. Transformações sócioterritoriais nas metrópoles de Buenos Aires, São Paulo e Santiago. In: Lencioni, S; Pereira, P.C.X. (Org.). Transformações sócioterritoriais nas metrópoles de Buenos Aires, São Paulo e Santiago. São Paulo: Paim. 7-20.

MARTINE. G. A Redistribuição Espacial da População Brasileira Durante a Década de 80. Texto para Discussão (IPEA), Rio de Janeiro, p. 1-46, 1994.

Disponível em: <http://www.ipea.gov.br/portal/images/stories/PDFs/TDs/td_0329.pdf> Acessado em: 05/06/2013.

MOURA, R. 2009. Arranjos urbano-regionais no Brasil: uma análise com foco em Curitiba. Tese (Doutorado em Geografia), Universidade Federal do Paraná, Curitiba.

PANIZZI. W. Os anos 90 urbanização Brasileira e o desafio das metrópoles. In: RIBEIRO, A. C. T. (Org.) ; MACHADO, D. B. P. (Org.) . Metropolização e rede urbana: perspectivas dos anos 90. Rio de Janeiro: IPPUR/UFRJ, 1990. 257p.

REIS, G, N. Notas sobre Urbanização Dispersa e Novas Formas de Tecido Urbano. São Paulo: Via das Artes, 2006.

SILVA, É. T. 2013. Estrutura urbana e mobilidade espacial nas metrópoles. Rio de Janeiro: Observatório das Metrópoles.

STORPER, Michael. A industrialização e a questão regional no Terceiro Mundo. In: VALADARES, Lícia.; PRETECEILLE, Edmond (coord). Reestruturação urbana: tendências e desafios. São Paulo: Nobel/IUPERJ, 1990, p. 120-147.

TOWNROE, P. M. e KEEN, D. Polarization reversal in the state of São Paulo. Regional Studies, v. 18, p.

45-54, 1984.

UNFPA. The State of World Population 2007: Unleashing the Potential of Urban Growth. New York: UNFPA, 2007. 